\title{
Análises técnicas e econômicas no sistema de integração lavoura-pecuária submetido à adubação nitrogenada ${ }^{1}$
}

\author{
Nídia Raquel Costa ${ }^{2}$, Marcelo Andreotti ${ }^{3}$, Máila Terra Gioia 4 , Maria Aparecida Anselmo Tarsitano ${ }^{5}$, \\ Cristiano Magalhães Pariz, Salatiér Buzetti ${ }^{3}$
}

\section{RESUMO}

Sustentabilidade agropecuária, redução nos custos de produção e agregação de valor ao sistema agrícola são alcançadas pelo uso das áreas durante todo o ano em sistemas integrados ou consorciados de produção. Este trabalho teve como objetivos determinar a matriz de coeficientes técnicos e estimar e avaliar o custo operacional total (COT) e os indicadores de lucratividade (IL) do consórcio do milho com duas espécies do gênero Brachiaria (B. brizantha cv, MG-5 e B. ruziziensis), submetidas a doses de N (0, 100, 200, 300 e $400 \mathrm{~kg} \mathrm{ha}^{-1}$ ano $\left.^{-1}\right)$ em cobertura, utilizando-se como fonte a ureia, e do feijoeiro de inverno em sucessão, na Integração Lavoura-Pecuária (ILP) em sistema plantio direto (SPD), no ano agrícola de 2008/2009, em condições irrigadas no Cerrado. O experimento foi instalado em delineamento experimental em blocos casualizados, com quatro repetições, em esquema fatorial 2 x 5 . Os insumos foram os componentes que mais oneraram o custo de produção do milho e feijão na ILP estudada. O COT aumentou de forma diretamente proporcional às doses de $\mathrm{N}$ em cobertura. Para todos os tratamentos os índices de lucratividade (IL) foram positivos, indicando a viabilidade da modalidade. $\mathrm{O}$ tratamento que apresentou melhores desempenhos técnico e econômico foi o milho em consórcio com B. brizantha, adubados com $100 \mathrm{~kg} \mathrm{ha}^{-1} \mathrm{ano}^{-1}$ de $\mathrm{N}$ e feijão em sucessão.

Palavras-chave: consórcio, doses de N, matriz de coeficientes técnicos, custo operacional total, indicadores de lucratividade.

\section{ABSTRACT}

\section{Technical and economic analysis in integrated crop-livestock submitted to nitrogen fertilization}

Sustainable agriculture, reduced production costs and adding value to the system are achieved through the use of agricultural areas throughout the year, in integrated or mixed system. The study aimed to determine the technical coefficients to estimate and evaluate the operational cost and profitability indicators of the consortium of corn with two species of Brachiaria (B. brizantha, MG-5 and B. ruziziensis). The crops were submitted to N rates (0, 100, 200, 300 e $400 \mathrm{~kg} \mathrm{ha}^{-1} \mathrm{year}^{-1}$ ) at sidedressing, using urea, and winter common bean in succession, in crop-livestock integration under no-tillage, in irrigated conditions, in 2008/2009 agricultural year in Cerrado region (Selvíria - MS). The experiment was conducted in a randomized complete block design with four replications in a $2 \mathrm{x} 5$ factorial. It was concluded that

\footnotetext{
Recebido para publicação em 21/03/2011 e aprovado em 04/10/2012.

${ }^{1}$ Parte da Dissertação de mestrado da primeira autora

${ }^{2}$ Engenheira-Agrônoma, Mestre. Faculdade de Engenharia de Ilha Solteira, Universidade Estadual Paulista, Avenida Brasil, 56, Centro, 15385-000, Ilha Solteira, São Paulo, Brasil. nidiar_costa@hotmail.com (autora para correspondência).

${ }^{3}$ Engenheiro-Agrônomo, Doutor. Faculdade de Engenharia de Ilha Solteira, Universidade Estadual Paulista, Avenida Brasil, 56, Centro, 15385-000, Ilha Solteira, São Paulo, Brasil. dreotti@agr.feis.unesp.br; sbuzetti@agr.feis.unesp.br

${ }^{4}$ Engenheira-Agrônoma. Faculdade de Engenharia de Ilha Solteira, Universidade Estadual Paulista, Avenida Brasil, 56, Centro, 15385-000, Ilha Solteira, São Paulo, Brasil. mailaterra@gmail.com

${ }^{5}$ Engenheira-Agrônoma, Doutora. Faculdade de Engenharia de Ilha Solteira, Universidade Estadual Paulista, Avenida Brasil, 56, Centro, 15385-000, Ilha Solteira, São Paulo, Brasil maat@agr.feis.unesp.br

${ }^{6}$ Zootecnista, Mestre. Faculdade de Medicina Veterinária e Zootecnia, Universidade Estadual Paulista, Distrito de Rubião Júnior, s/n, 18618-970, Botucatu, São Paulo, Brasil. cmpzoo@gmail.com
} 
the inputs were the components that most increased the producing cost of corn and common bean in the ILP study. The total operational cost has increased as a function of increasing doses of N. In all treatments the levels of profitability were positive indicating the viability of the system. The treatment that showed the best technical and economic performance was intercropped with corn and B. brizantha, fertilized with $100 \mathrm{~kg} \mathrm{ha}^{-1} \mathrm{year}^{-1} \mathrm{~N}$ and common bean in succession.

Key words: consortium, $\mathrm{N}$ doses, technical coefficients, total operating cost, profitability indicators.

\section{INTRODUÇÃO}

Devido aos grandes investimentos necessários para a formação, recuperação, reforma, adubação e irrigação de pastagens, têm-se buscado diversas técnicas visando à diminuição desses custos, tendo o sistema de Integração Lavoura-Pecuária (ILP) em sistema plantio direto (SPD), em diversas regiões do mundo, tornado-se opção vantajosa, beneficiando duas atividades de elevado interesse econômico, a produção de grãos e a pecuária, além de proporcionar resultados socioeconômicos e ambientais positivos aos sistemas produtivos (Kluthcouski et al., 2000; Landers, 2007; Tracy \& Zhang, 2008).

Conforme Martha Júnior \& Vilela (2007), a ILP passa a ser alternativa para viabilizar a correção da fertilidade do solo em pastagens e minimizar o risco de oscilações nos preços dos fertilizantes nos empreendimentos pastoris, visto que o preço relativo insumo-produto na produção de grãos tem sido mais estável do que na pecuária. Portanto, o risco associado ao uso de fertilizantes em pastagens na ILP é reduzido, em resposta a um ambiente menos dependente do uso desses insumos, sendo que, com exceção ao $\mathrm{N}$, geralmente o efeito residual das adubações na cultura de grãos dispensa, em curto e médio prazos (um a dois anos e meio), a adubação com $\mathrm{P}$ e bases trocáveis $\left(\mathrm{Ca}^{2+}, \mathrm{Mg}^{2+} \mathrm{e} \mathrm{K}^{+}\right)$.

No Cerrado, o cultivo de culturas graníferas no outono (safrinha) pode ser inviabilizado principalmente por déficits hídricos. Assim, o consórcio de milho com forrageiras perenes, principalmente às do gênero Brachiaria no verão, é uma opção para produção de forragem do outono à primavera (Kluthcouski \& Yokoyama, 2003), em que o corte dessa para fornecimento como volumoso aos animais é uma alternativa ao invés de armazenálas na forma de silagem. No entanto, de acordo com Pariz et al. (2009), apesar das vantagens que esse sistema pode proporcionar em relação a sistemas não integrados de produção, seu sucesso depende do adequado conhecimento sobre o sistema como um todo.

Dessa maneira, dentre as espécies mais utilizadas em consórcio na ILP destaca-se a cultura do milho, que é o cereal mais produzido no Brasil, com área cultivada na safra 2009/2010 de 7.724 mil hectares, ou seja, com redu- ção de 16,7\% em relação à área na safra 2008/2009. A produtividade média de grãos foi de $4.412 \mathrm{~kg} \mathrm{ha}^{-1}$, correspondendo a um aumento de $21,5 \%$, comparado à produtividade alcançada na safra anterior. Considerando-se a terceira safra de feijão em 2009/2010 ("feijão de inverno"), a área cultivada foi de 721,9 mil hectares, valor esse 5,9\% menor ao obtido na safra anterior, com produtividade média de $1.079 \mathrm{~kg} \mathrm{ha}^{-1}$ (CONAB, 2010).

Richetti \& Ceccon (2010), avaliando o custo de produção do milho safrinha em consórcio com a B. ruziziensis, não verificaram diferença significativa em comparação ao milho cultivado sem o consórcio. Os autores ressaltam ainda que a utilização de tecnologia de forma criteriosa resultou, quase sempre, em uso mais adequado de insumos e, por consequência, em menor custo de produção, destacando ainda os benefícios advindos desse sistema produtivo para manutenção do SPD pela palhada resultante das forrageiras em consórcio. Da mesma forma, Muniz et al. (2007), Macedo (2009) e Garcia et al. (2012) demonstraram que a ILP é uma atividade economicamente lucrativa, sendo uma opção viável para investidores do agronegócio na região dos Cerrados.

O objetivo deste trabalho foi determinar a matriz de coeficientes técnicos, assim como estimar e avaliar o custo operacional total e os indicadores de lucratividade do consórcio da cultura do milho com duas espécies do gênero Brachiaria (B. brizantha cv, MG-5 e B. ruziziensis), submetidas a doses crescentes de $\mathrm{N}$ em cobertura, e do feijoeiro de inverno em sucessão, no sistema de Integração Lavoura-Pecuária (ILP) em sistema plantio direto (SPD), no ano agrícola de 2008/2009.

\section{MATERIAL E MÉTODOS \\ Condução do experimento e levantamento dos dados}

O experimento foi conduzido no ano agrícola de 2008/ 2009, na Fazenda de Ensino, Pesquisa e Extensão, pertencente à Faculdade de Engenharia, Campus de Ilha Solteira (FE/Unesp), área de Produção Vegetal, localizada no município de Selvíria, Estado de Mato Grosso do Sul ( $20^{\circ} 20^{\prime} 05^{\prime \prime} \mathrm{S}$ e $51^{\circ} 24^{\prime} 26^{\prime \prime} \mathrm{W}$, altitude de $\left.335 \mathrm{~m}\right)$. O tipo climático é Aw, segundo classificação de Köppen, ca- 
racterizado como tropical úmido com estação chuvosa no verão e seca no inverno.

A área experimental encontrava-se sob sistema plantio direto (SPD) há oito anos, com culturas anuais e perenes para formação de palhada, sendo a cultura anterior feijão de inverno. A área foi irrigada por aspersão (pivô central), quando necessário, em razão de déficits hídricos, durante todo o período experimental. O solo da área é um Latossolo Vermelho distroférrico, classificado conforme Santos et al (2006). Os dados de temperatura e precipitação pluvial durante o período de desenvolvimento do experimento constam na Figura 1.

Os tratamentos constituíram-se do consórcio da cultura do milho (híbrido simples DKB 390 YG) com duas espécies do gênero Brachiaria (B. brizantha cv. MG-5 e B. ruziziensis), adubados com doses de $\mathrm{N}$ em cobertura; posteriormente foi realizada a semeadura do feijoeiro de inverno (cv. Pérola) em sucessão. Portanto, o delineamento experimental utilizado foi o de blocos casualizados, com quatro repetições, em esquema fatorial 2 x 5; ou seja, duas espécies forrageiras e cinco doses de nitrogênio. Cada unidade experimental (parcela) foi constituída por 3,6 m de largura $x 10 \mathrm{~m}$ de comprimento, totalizando $36 \mathrm{~m}^{2}$.

A nomenclatura utilizada no presente trabalho corresponde e difere entre si pelas espécies forrageiras e doses de $\mathrm{N}$ aplicadas em cobertura: 1 ) $\mathrm{M} / \mathrm{Bb}-\mathrm{F} 0=$ milho em consórcio com $B$. brizantha, sem $\mathrm{N}$ em cobertura e feijão em sucessão; 2) M/Bb-F 1 = milho em consórcio com $B$. brizantha, $100 \mathrm{~kg} \mathrm{ha}^{-1} \mathrm{ano}^{-1}$ de $\mathrm{N}$ e feijão em sucessão; 3 ) M/Bb-F 2 = milho em consórcio com B. brizantha, $200 \mathrm{~kg} \mathrm{ha}^{-1} \mathrm{ano}^{-1}$ de $\mathrm{N}$ e feijão em sucessão; 4) M/Bb-F $3=$ milho em consórcio com $B$. brizantha, $300 \mathrm{~kg} \mathrm{ha}^{-1} \mathrm{ano}^{-1} \mathrm{de}$ $\mathrm{N}$ e feijão em sucessão; 5) M/Bb-F 4 = milho em consórcio com B. brizantha, $400 \mathrm{~kg} \mathrm{ha}^{-1} \mathrm{ano}^{-1}$ de $\mathrm{N}$ e feijão em sucessão; 6) M/Br-F 0 = milho em consórcio com $B$. ruziziensis, sem $\mathrm{N}$ em cobertura e feijão em sucessão; 7) M/Br-F 1 = milho em consórcio com B. ruziziensis, $100 \mathrm{~kg} \mathrm{ha}^{-1} \mathrm{ano}^{-1} \mathrm{de}$ $\mathrm{N}$ e feijão em sucessão; 8) M/Br-F 2 = milho em consórcio com $B$. ruziziensis, $200 \mathrm{~kg} \mathrm{ha}^{-1} \mathrm{ano}^{-1}$ de $\mathrm{N}$ e feijão em sucessão; 9) M/Br-F 3 = milho em consórcio com B. ruziziensis, $300 \mathrm{~kg} \mathrm{ha}^{-1} \mathrm{ano}^{-1}$ de N e feijão em sucessão; e 10) M/Br-F 4 = milho em consórcio com B. ruziziensis, $400 \mathrm{~kg} \mathrm{ha}^{-1} \mathrm{ano}^{-1}$ de $\mathrm{N}$ e feijão em sucessão, respectivamente. A adubação nitrogenada foi parcelada em duas épocas distintas, sendo metade da dose de $\mathrm{N}$ aplicada em cobertura no consórcio milho/Brachiaria e a outra metade em cobertura nas espécies forrageiras após a colheita do milho.

Antes da semeadura do milho (10/11/2008), as plantas daninhas da área foram dessecadas com herbicida Glyphosate na dose de 1.440 g i.a. ha-1 ${ }^{-1}$ A cultura do milho foi semeada mecanicamente com uso de semeadoraadubadora com mecanismo sulcador tipo haste (facão) para SPD no dia 18/11/2008, a uma profundidade de aproximadamente $0,05 \mathrm{~m}$, espaçamento de $0,90 \mathrm{~m}$ e cerca de 5,4 sementes $\mathrm{m}^{-1}$, objetivando-se atingir um estande final próximo a 55.000 plantas ha ${ }^{-1}$. Foi realizada adubação de semeadura no milho com aplicação de $300 \mathrm{~kg} \mathrm{ha}^{-1}$ do formulado 08-28-16 (24 kg ha-1 de N, $84 \mathrm{~kg} \mathrm{ha}^{-1} \mathrm{de}_{2} \mathrm{O}_{5}$ e $48 \mathrm{~kg}$ $\mathrm{ha}^{-1}$ de $\mathrm{K}_{2} \mathrm{O}$, respectivamente). Como tratamento de sementes na cultura do milho, foi feita a aplicação de $150 \mathrm{~g}$ $\mathrm{L}^{-1}$ i. a. imidacloprido $+450 \mathrm{~g} \mathrm{~L}^{-1}$ i.a. tiodicarbe.

A semeadura das forrageiras foi realizada simultaneamente ao milho, sendo efetuada com outra semeadoraadubadora com mecanismo sulcador do tipo disco duplo desencontrado para SPD. Para tanto, foram semeadas duas linhas dos capins nas entrelinhas da cultura produtora de grãos. As sementes foram depositadas na profundidade de aproximadamente $0,08 \mathrm{~m}$, espaçadas em 0,34 m, utilizando-se cerca de $7 \mathrm{~kg} \mathrm{ha}^{-1}$ de sementes puras viáveis ( $\mathrm{VC}=76 \%$ ), localizando-se, dessa forma, abaixo da semente de milho, seguindo as recomendações de Kluthcouski et al. (2000).

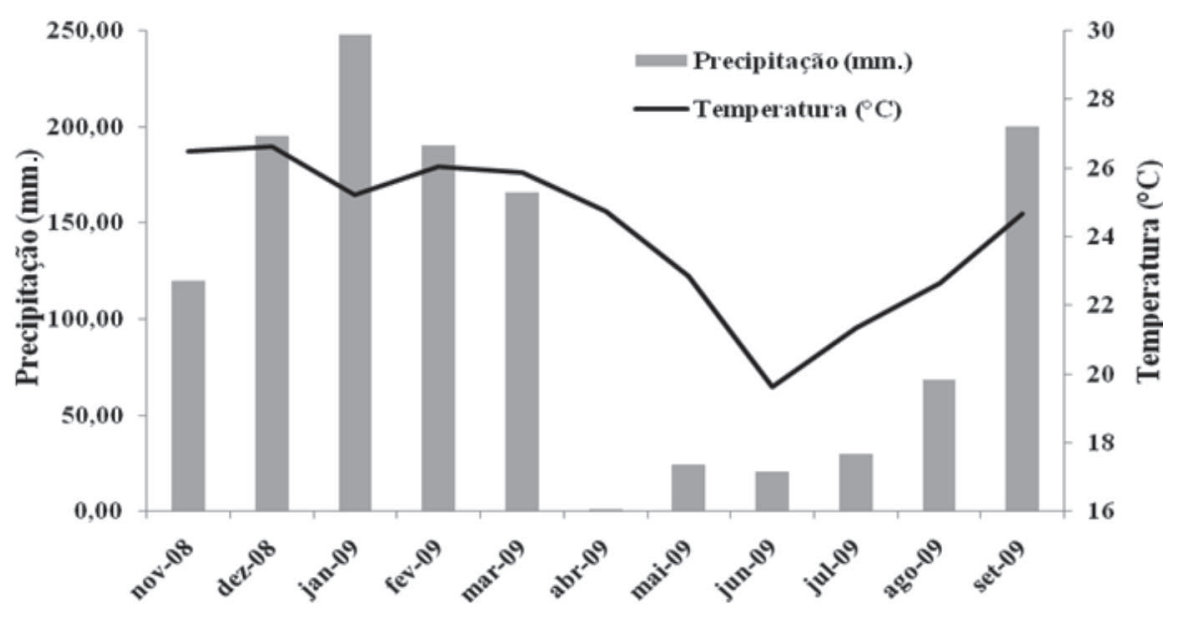

Figura 1. Dados climáticos levantados na estação meteorológica situada na Fazenda de Ensino, Pesquisa e Extensão da FE/UNESP, no município de Selvíria, MS. Período de novembro/2008 a setembro/2009. 
Em 23/12/2008, quando a cultura do milho atingiu o estádio fenológico V4 (quatro folhas totalmente desenvolvidas), procedeu-se a adubação de cobertura, aplicando-se manualmente a lanço as doses de 50,100, $150 \mathrm{e}$ $200 \mathrm{~kg} \mathrm{ha}^{-1}$ de N, além da testemunha (ausência de adubação nitrogenada). A adubação de cobertura foi realizada perto das linhas do milho, utilizando-se a ureia (45\% de N) como fonte, irrigando-se em seguida a área experimental, evitando assim perdas excessivas de $\mathrm{N}$ por volatilização.

A colheita manual do milho para avaliação da produtividade de grãos (área útil da parcela, constituída pelas duas linhas centrais, desprezando-se um metro em cada extremidade) foi realizada em 25/03/2009, correspondendo a 121 dias após a emergência (DAE) do milho. Assim, a produtividade de grãos foi determinada colhendo-se manualmente todas as espigas das plantas contidas na área útil da parcela, e após a colheita as espigas foram debulhadas mecanicamente, pesando-se os grãos. Posteriormente calculou-se a produtividade em $\mathrm{kg} \mathrm{ha}^{-1}$ corrigida para o teor de $13 \%$ de umidade.

Após a operação de colheita do milho (25/03/2009), as plantas forrageiras foram uniformizadas com roçadora mecânica, adotando-se como referência aproximadamente $0,25 \mathrm{~m}$ em relação à superfície do solo. Esse manejo teve por objetivo estimular o perfilhamento e padronizar a idade fenológica dos capins, simulando um corte de homogeneização sem remoção do material da área, permanecendo a palhada sobre a superfície do solo.

No dia 29/04/2009, procedeu-se então a adubação das plantas forrageiras com as doses de 50,100, 150 e $200 \mathrm{~kg}$ $\mathrm{N}_{\text {ha }}{ }^{-1}$, além da testemunha sem $\mathrm{N}$, utilizando-se como fonte a ureia ( $45 \%$ de $\mathrm{N})$, a qual foi aplicada manualmente a lanço, irrigando-se a área em seguida.

Foram realizadas amostragens para determinação da produtividade de massa seca (PMS) cerca de 40 dias após a adubação nitrogenada (08/06/2009), antes da área ser manejada com triturador horizontal de resíduos vegetais (Triton), realizando-se assim um segundo corte.

Em 08/06/2009 as plantas forrageiras da área foram dessecadas com herbicida Glyphosate na dose de 1.440 g i.a. ha ${ }^{-1} \mathrm{e}$, posteriormente, o feijão foi semeado mecanicamente com uso de semeadora-adubadora com mecanismo sulcador do tipo haste (facão) para SPD no dia 19/06/2009, em espaçamento de $0,45 \mathrm{~m}$, distribuindo-se aproximadamente 15 sementes $\mathrm{m}^{-1}$. Foi feita adubação

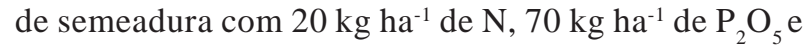
$40 \mathrm{~kg} \mathrm{ha}^{-1}$ de $\mathrm{K}_{2} \mathrm{O}$, com aplicação de $250 \mathrm{~kg} \mathrm{ha}^{-1}$ do formulado 8-28-16. Como tratamento de sementes utilizaram-se $50 \mathrm{~g}$ i.a. Carboxina $+50 \mathrm{~g}$ i.a. Tiram $/ 100 \mathrm{~kg}$ de sementes. Como adubação em cobertura aos 30 dias após a emergência utilizaram-se $70 \mathrm{~kg} \mathrm{ha}^{-1} \mathrm{de} \mathrm{N}$ na forma de ureia.
Durante o período de desenvolvimento do feijoeiro, foi realizado o controle fitossanitário, conforme as necessidades da cultura. Para tanto, aos 30 e 45 DAE do feijoeiro, aplicaram-se $10 \mathrm{~g} \mathrm{~L}^{-1}$ i. a. deltametrina $+350 \mathrm{~g} \mathrm{~L}^{-1}$ i. a. triazofós e a mistura de $12,5 \mathrm{~g} \mathrm{~L}^{-1}$ i.a. beta-ciflutrina +100 $\mathrm{g} \mathrm{L}^{-1}$ i.a. imidacloprido e $800 \mathrm{~g} \mathrm{~kg}^{-1}$ i. a. de mancozebe, respectivamente.

Ao final do ciclo da cultura (17/09/2009), as plantas da área útil de cada parcela (quatro linhas centrais com $2 \mathrm{~m}$ de comprimento) foram colhidas, trilhadas mecanicamente, pesadas e, posteriormente, calculada a produtividade de grãos e extrapolada para $\mathrm{kg} \mathrm{ha}^{-1}$ (13\% base úmida).

\section{Estrutura do custo de produção e avaliação econômica}

A metodologia para avaliação do cálculo de custo utilizada foi a do custo operacional de produção de acordo com Montes et al. (2006), que é constituído da soma das despesas diretas de custeio: operações realizadas, insumos (adubos, sementes, defensivos etc.), mão de obra, maquinário e irrigação, denominada de custo operacional efetivo (COE). Para as despesas indiretas, como depreciações, encargos sociais e financeiros, considerou-se 5\% do COE, resultando, portanto, no custo operacional total (COT).

Os indicadores de lucratividade foram calculados conforme a metodologia de Martin et al. (1998); ou seja, calcularam-se a renda bruta (RB), o lucro operacional (LO) e índice de lucratividade (IL). Para a elaboração dos custos de produção de cada tratamento, bem como dos indicadores de lucratividade, consideraram-se os preços pagos em 2009 (Agrianual, 2009; CONAB, 2010) ajustados àqueles vigentes em lavouras comerciais em São Paulo para o ano agrícola 2008/2009.

A receita bruta (RB) do milho e do feijão foi estimada pela produtividade média obtida em cada tratamento, multiplicando-se pelo preço pago aos produtores e somado às receitas dos dois cultivos realizados durante o ano. A receita que seria proveniente da engorda do gado com fornecimento da forragem não foi considerada, pois o objetivo deste trabalho foi avaliar a viabilidade da atividade no domínio das culturas produtoras de grãos, visando, principalmente, à formação de palhada para o SPD.

\section{RESULTADOS E DISCUSSÃO}

Na Tabela 1 constam a matriz de coeficientes técnicos, os valores obtidos na realização de cada operação e a estimativa do custo operacional total (COT) detalhado para a produção do tratamento $\mathrm{M} / \mathrm{Bb}-\mathrm{F} 1$ (milho em consórcio com B. brizantha, $100 \mathrm{~kg} \mathrm{ha}^{-1}$ ano ${ }^{-1}$ de $\mathrm{N}$ e feijão em sucessão). Vale ressaltar ainda que a adubação nitrogenada foi parcelada em duas épocas, sendo metade da dose apli- 
cada em cobertura no consórcio milho/Brachiaria e o restante em cobertura nas espécies forrageiras após a colheita do milho em todos os tratamentos, respectivamente. Os resultados obtidos no experimento foram extrapolados para um hectare.

Verifica-se que o custo operacional efetivo (COE), que é composto por despesas com as operações e insumos, foi de R \$ 4.156,27 ha ${ }^{-1}$ e o custo operacional total (COT), de $\mathrm{R} \$ 4.364,08 \mathrm{ha}^{-1}$. Nas operações que compõem o COE, destacam-se os custos com a colheita do feijão e a irrigação, totalizando 20,68\% dos gastos, uma vez que para a obtenção das altas produtividades de grãos verificadas e época de cultivo (feijão de inverno), além das características da região em estudo (Cerrado), foi necessária a adoção dessa tecnologia (irrigação).

No entanto, para as despesas com insumos, destacam-se os adubos formulados e os herbicidas, responsáveis por $56,61 \%$ do COE. Dessa maneira, os insumos foram os componentes que mais oneraram o custo de produção no sistema de ILP analisado, totalizando aproximadamente 56,41\% do COT. Tal fato ocorreu, provavelmente, em razão da grande exigência por nutrientes no consórcio da cultura do milho com as forrageiras, demandando, assim, grande quantidade de adubo para elevadas pro-

Tabela 1. Estimativa do custo operacional total das culturas do milho, braquiária e feijão para o tratamento M/Bb-F 1 em um hectare. Selvíria, Mato Grosso do Sul, 2008/2009

\begin{tabular}{|c|c|c|c|c|}
\hline Descrição & Especificação & Coeficiente & Valor unitário & Valor total \\
\hline \multicolumn{5}{|l|}{ A - Operações } \\
\hline Dessecação (2x) & $\mathrm{HM}$ & 0,5 & 45,00 & 45,00 \\
\hline Semeadura do milho & $\mathrm{HM}$ & 1,0 & 115,00 & 115,00 \\
\hline Adubação e semeadura da forrageira & $\mathrm{HM}$ & 1,0 & 115,00 & 115,00 \\
\hline Adubação de cobertura do milho & $\mathrm{HM}$ & 1,0 & 45,00 & 45,00 \\
\hline Colheita do milho & $\mathrm{HM}$ & 0,6 & 140,00 & 84,00 \\
\hline Roçagem de homogeneização & $\mathrm{HM}$ & 1,0 & 65,00 & 65,00 \\
\hline Adubação de cobertura braquiária & $\mathrm{HM}$ & 0,5 & 38,00 & 19,00 \\
\hline Corte da braquiária & $\mathrm{HM}$ & 1,0 & 65,00 & 65,00 \\
\hline Semeadura e adubação do feijão & $\mathrm{HM}$ & 0,8 & 95,00 & 76,00 \\
\hline Adubação de cobertura do feijão & $\mathrm{HM}$ & 0,8 & 45,00 & 36,00 \\
\hline Pulverização (2x) & $\mathrm{HM}$ & 1,0 & 85,00 & 170,00 \\
\hline Colheita do feijão (empreita) & - & - & 450,00 & 450,00 \\
\hline Irrigação (pivô) & $\mathrm{mm}$ & 150,0 & 2,73 & 409,50 \\
\hline Subtotal A & & & & 1694,5 \\
\hline \multicolumn{5}{|l|}{ B - Insumos } \\
\hline \multicolumn{5}{|l|}{ B1 - Fertilizantes } \\
\hline Adubo N-P-K (08-28-16) & $\mathrm{kg}$ & 550,0 & 2,00 & $1.100,00$ \\
\hline Ureia (cobertura feijão e doses) & $\mathrm{kg}$ & 377,7 & 0,84 & 317,27 \\
\hline \multicolumn{5}{|l|}{ B2 - Sementes } \\
\hline milho DKB390 YG & $\mathrm{sc}(20 \mathrm{~kg})$ & 1,0 & 400,00 & 400,00 \\
\hline B. brizanta cv. MG-5 & $\mathrm{kg}$ & 7,0 & 10,50 & 73,50 \\
\hline feijão cv. Pérola & $\mathrm{sc}(40 \mathrm{~kg})$ & 1,5 & 180,00 & 270,00 \\
\hline \multicolumn{5}{|l|}{ B3 - Defensivos } \\
\hline Herbicida Glyphosate $(2 \mathrm{x})$ & 1 & 4,0 & 24,00 & 192,00 \\
\hline Cropstar & 1 & 0,3 & 90,00 & 27,00 \\
\hline Vitavax + Thiran 200 SC & 1 & 0,5 & 32,00 & 16,00 \\
\hline Deltaphos EC & 1 & 0,5 & 45,00 & 22,50 \\
\hline Connect & 1 & 0,5 & 35,00 & 17,50 \\
\hline Dithane M-45 & $\mathrm{kg}$ & 2,0 & 13,00 & 26,00 \\
\hline Subtotal B & & & & $2.461,77$ \\
\hline Custo operacional efetivo $(\mathrm{A}+\mathrm{B})$ & & & & $4.156,27$ \\
\hline \multicolumn{5}{|l|}{ C- Outras despesas } \\
\hline Subtotal C & & & & 207,81 \\
\hline Custo operacional total $(\mathrm{A}+\mathrm{B}+\mathrm{C})$ & & & & $4.364,08$ \\
\hline
\end{tabular}


dutividades de grãos. É provável que as forrageiras em consórcio tenham se beneficiado do efeito residual desses fertilizantes, tendo em vista as altas produtividades de massa seca (PMS) obtidas no período de avaliação (Tabela 2).

As espécies forrageiras utilizadas neste trabalho tiveram como principal finalidade a formação de palhada para a manutenção e continuidade do SPD, fatores esses extremamente importantes levando-se em consideração as possíveis melhorias nos atributos químicos, físicos e biológicos do solo. A presença da palhada das espécies forrageiras na área em estudo proporcionou, ainda, elevada produtividade do feijoeiro de inverno em sucessão. Tal fato deve-se, provavelmente, ao processo de decomposição e mineralização dos resíduos vegetais (palhada), pelo aproveitamento de adubações residuais e pela própria adubação de semeadura na cultura do feijão.

Dessa maneira torna-se indispensável ao agricultor, anteriormente à instalação desse sistema de produção, a avaliação das necessidades das culturas a serem implantadas, das condições ambientais características de cada região, dos aspectos tecnológicos e do capital disponível para que sejam alcançadas altas produtividades e lucratividade nos sistemas de cultivo, em que as plantas forrageiras em crescimento, após a colheita da cultura do milho, além de servir como excelente cobertura do solo beneficiando as culturas cultivadas em sucessão como no presente trabalho, possam também ser disponibilizadas aos animais em pastejo ou fornecidas como alimento volumoso no cocho, demonstrando, dessa maneira, as inúmeras vantagens desse sistema de produção.
Portanto, sistemas de ILP, além de promoverem maior adoção de tecnologias pelos produtores, beneficiam também o sistema de produção como um todo, melhorando os atributos do solo (Anghinoni, 2007), além de garantirem melhor ocupação da área agrícola durante todo o ano. Igualmente, o presente trabalho foi instalado visando à produtividade de grãos de milho e, com a palhada formada pelas forrageiras, após o consórcio, dar continuidade na sucessão/rotação de culturas objetivando a sustentabilidade do SPD; neste caso, com cultivo do feijoeiro de inverno.

$\mathrm{Na}$ Tabela 2 constatam-se os valores de produtividade $\left(\mathrm{kg} \mathrm{ha}^{-1}\right)$, os custos $\left(\mathrm{R} \$ \mathrm{~kg}^{-1}\right)$ referentes às culturas do milho e feijão, à produtividade de massa seca (PMS) das espécies forrageiras após o consórcio com o milho, à receita bruta (RB) obtida no ano agrícola de referência, ao custo operacional total (COT), lucro operacional (LO) e ao índice de lucratividade (IL) para cada tratamento estudado.

Dessa maneira, o preço médio de grãos de milho de $\mathrm{R} \$$ $0,25 \mathrm{~kg}^{-1}(\mathrm{R} \$ 15,00 / \mathrm{saca}$ de $60 \mathrm{~kg})$ representa o preço médio da Política de Garantia dos Preços Mínimos (PGPM) dos últimos três anos (2008, 2009 e 2010). Para o feijão, o preço médio de $\mathrm{R} \$ 1,30 \mathrm{~kg}^{-1}$ ( $\mathrm{R} \$ 78,00 / \mathrm{saca}$ de $60 \mathrm{~kg}$ ) é semelhante ao preço mínimo da PGPM também para os três últimos anos.

Verifica-se que o tratamento M/Bb-F 0 (milho em consórcio com B. brizantha, sem $\mathrm{N}$ em cobertura e feijão em sucessão) apresentou COT de R \$ 4.168,10. Em contrapartida, constata-se um aumento para $\mathrm{R} \$ 4.952,02$ no tratamento M/Bb-F 4 (milho em consórcio com B. brizantha, $400 \mathrm{~kg} \mathrm{ha}^{-1}$ ano $^{-1}$ de $\mathrm{N}$ e feijão em sucessão). Assim, den-

Tabela 2. Produtividade do milho e feijão, preços pagos ao produtor na região, produtividade de massa seca (PMS) das forrageiras, custo operacional total (COT), receita bruta (RB), lucro operacional (LO) e indicadores de lucratividade (IL). Selvíria, Mato Grosso do Sul, 2008/2009

\begin{tabular}{|c|c|c|c|c|c|c|c|c|c|}
\hline Trat.* & $\begin{array}{c}\text { Prod.milho } \\
\text { (kg/ha) }\end{array}$ & $\begin{array}{c}\text { Millho } \\
\text { R\$/kg }\end{array}$ & Prod.feijão & $\begin{array}{l}\text { Feijão } \\
\text { R\$/kg }\end{array}$ & $\begin{array}{c}\text { PMS } \\
\text { (kg/ha) }\end{array}$ & $\begin{array}{c}\text { COT } \\
(\mathbf{R} \$ / \mathbf{h a})\end{array}$ & $\begin{array}{c}\mathbf{R B} \\
(\mathbf{R} \$ / \mathbf{h a})\end{array}$ & $\begin{array}{c}\text { LO } \\
\text { (R\$/ha) }\end{array}$ & $\begin{array}{l}\mathrm{IL} \\
(\%)\end{array}$ \\
\hline M/Bb-F 0 & $6.330,55$ & 0,25 & $3.604,17$ & 1,30 & 5.350 & $4.168,10$ & $6.268,05$ & $2.099,95$ & 33,50 \\
\hline M/Bb-F 1 & $8.397,21$ & 0,25 & $4.208,33$ & 1,30 & 5.250 & $4.364,08$ & $7.570,13$ & $3.206,05$ & 42,35 \\
\hline M/Bb-F 2 & $7.271,11$ & 0,25 & $3.861,11$ & 1,30 & 6.400 & $4.560,06$ & $6.837,22$ & $2.277,16$ & 33,30 \\
\hline M/Bb-F 3 & $7.488,61$ & 0,25 & $4.104,17$ & 1,30 & 6.250 & $4.756,04$ & $7.207,57$ & $2.451,52$ & 34,01 \\
\hline M/Bb-F 4 & $8.369,16$ & 0,25 & $4.076,39$ & 1,30 & 6.750 & $4.952,02$ & $7.391,59$ & $2.439,57$ & 33,00 \\
\hline M/Br-F 0 & $6.253,33$ & 0,25 & $4.097,22$ & 1,30 & 5.800 & $4.142,37$ & $6.889,71$ & $2.747,34$ & 39,87 \\
\hline M/Br-F 1 & $6.791,11$ & 0,25 & $4.409,72$ & 1,30 & 6.100 & $4.338,35$ & $7.430,41$ & $3.092,05$ & 41,61 \\
\hline M/Br-F 2 & $6.897,78$ & 0,25 & $4.368,05$ & 1,30 & 5.700 & $4.534,33$ & $7.402,91$ & $2.868,57$ & 38,75 \\
\hline M/Br-F 3 & $5.534,16$ & 0,25 & $4.326,39$ & 1,30 & 5.650 & $4.730,31$ & $7.007,84$ & $2.277,52$ & 32,49 \\
\hline M/Br-F 4 & $7.556,38$ & 0,25 & $4.048,61$ & 1,30 & 5.050 & $4.926,29$ & $7.152,28$ & $2.225,98$ & 31,12 \\
\hline
\end{tabular}

*Tratamentos: 1) M/Bb-F 0 = milho em consórcio com B. brizantha, sem N em cobertura e feijão em sucessão; 2) M/Bb-F $\mathbf{1}=$ milho em consórcio com B. brizantha, $100 \mathrm{~kg} \mathrm{ha}^{-1} \mathrm{ano}^{-1}$ de $\mathrm{N}$ e feijão em sucessão; 3) M/Bb-F 2 = milho em consórcio com B. brizantha, $200 \mathrm{~kg}$ ha${ }^{1}$ ano $^{-1}$ de N e feijão em sucessão; 4) M/Bb-F 3 = milho em consórcio com $B$. brizantha, $300 \mathrm{~kg} \mathrm{ha}^{-1} \mathrm{ano}^{-1}$ de $\mathrm{N}$ e feijão em sucessão; 5) M/ Bb-F 4 = milho em consórcio com $B$. brizantha, $400 \mathrm{~kg} \mathrm{ha}^{-1}$ ano $^{-1}$ de $\mathrm{N}$ e feijão em sucessão; $\left.\mathbf{6}\right) \mathrm{M} / \mathbf{B r}-\mathbf{F} \mathbf{0}=$ milho em consórcio com $B$. ruziziensis, sem $\mathrm{N}$ em cobertura e feijão em sucessão; 7) M/Br-F $\mathbf{1}=$ milho em consórcio com B. ruziziensis, $100 \mathrm{~kg} \mathrm{ha}^{-1} \mathrm{ano}^{-1}$ de $\mathrm{N}$ e feijão em sucessão; 8) M/Br-F 2 = milho em consórcio com B. ruziziensis, $200 \mathrm{~kg} \mathrm{ha}^{-1}$ ano ${ }^{-1}$ de $\mathrm{N}$ e feijão em sucessão; 9) $\mathbf{M} / \mathbf{B r}-\mathbf{F} \mathbf{3}=\mathrm{milho} \mathrm{em}$ consórcio com B. ruziziensis, $300 \mathrm{~kg} \mathrm{ha}^{-1} \mathrm{ano}^{-1}$ de N e feijão em sucessão; 10) $\mathbf{M} / \mathbf{B r}-\mathbf{F} \mathbf{4}=$ milho em consórcio com B. ruziziensis, $400 \mathrm{~kg}$ ha $^{-1} \mathrm{ano}^{-1}$ de $\mathrm{N}$ e feijão em sucessão.

Rev. Ceres, Viçosa, v. 59, n.5, p. 597-605, set/out, 2012 
tro dos tratamentos com a espécie forrageira B. brizantha ocorreu variação nos gastos de $15,80 \%$ (Tabela 2). Nas condições em que o experimento foi realizado, observa-se que o COT aumentou de forma diretamente proporcional às doses de $\mathrm{N}$ nos tratamentos.

Da mesma forma, para a B. ruziziensis, o COT foi aumentado de $\mathrm{R} \$ 4.142,38$ para o tratamento M/Br-F 0 (milho em consórcio com $B$. ruziziensis, sem $\mathrm{N}$ em cobertura e feijão em sucessão) para $\mathrm{R} \$ 4.926,30$ no tratamento $\mathrm{M} / \mathrm{Br}$ F 4 (milho em consórcio com B. ruziziensis, $400 \mathrm{~kg} \mathrm{ha}^{-1}$ ano $^{-1}$ de $\mathrm{N}$ e feijão em sucessão); ou seja, aumento de $18,92 \%$ nos custos.

Entre os tratamentos, a produtividade do milho variou de $6.253 \mathrm{~kg} \mathrm{ha}^{-1}$ no M/Br-F 0 (milho em consórcio com $B$. ruziziensis, sem $\mathrm{N}$ em cobertura e feijão em sucessão) a $8.397 \mathrm{~kg} \mathrm{ha}^{-1}$ no M/Bb-F 1 (milho em consórcio com $B$. brizantha, $100 \mathrm{~kg} \mathrm{ha}^{-1}$ ano $^{-1}$ de $\mathrm{N}$ e feijão em sucessão), portanto $25,54 \%$.

De maneira geral, a produtividade de grãos não foi influenciada pelos consórcios, demonstrando que a competição existente entre as espécies consorciadas não prejudicou esse atributo, tendo em vista as altas produtividades obtidas nesse sistema de produção. Em algumas situações, pesquisadores relataram que a presença da forrageira não afetou a produtividade de grãos de milho (Pariz et al., 2009; Richetti \& Ceccon, 2010; Garcia et al., 2012); porém, em alguns casos, houve necessidade da aplicação de herbicida nicosulfuron em subdoses para reduzir o crescimento da forrageira, como forma de garantir o pleno desenvolvimento do milho (Borghi \& Crusciol, 2007), o que não ocorreu no presente trabalho.

De acordo com Kluthcouski \& Aidar (2003), avaliando a produtividade de grãos de 18 cultivares de milho em consórcio com forrageiras na estação chuvosa em diferentes locais, em geral a competição interespecífica não reduziu significativamente a produtividade de grãos. Verificaram também que, na maioria dos locais, ocorreram tendências ao aumento de produtividade no sistema consorciado, provavelmente em razão da não aplicação de herbicida graminicida em pós-emergência, que reduziu possíveis efeitos fitotóxicos ao milho. Em experimentos mais recentes, em que há maior adoção de tecnologias adequadas às condições do Cerrado e com foco também na produção de grãos, a produtividade do milho consorciado com plantas do gênero Brachiaria é alta (em geral, acima de $6 \mathrm{t} \mathrm{ha}^{-1}$ ) e, muitas vezes, supera as obtidas em cultivo solteiro.

Dessa maneira, a produtividade média do milho foi de $7.571 \mathrm{~kg} \mathrm{ha}^{-1}$ no consórcio com a $B$. brizantha, cerca de $12,74 \%$ maior que a produtividade média de grãos obtida no consórcio com a $B$. ruziziensis, que foi de aproximadamente $6.607 \mathrm{~kg} \mathrm{ha}^{-1}$ (Tabela 2). Tal fato se deve, em parte, à maior competição da $B$. ruziziensis comparada à $B$. brizantha. Essa competição pode comprometer a translocação de fotoassimilados para os grãos, consequentemente afetando os componentes da produção. Entretanto, essa redução causada pela competição entre as espécies consorciadas não interferiu na lucratividade do sistema.

De acordo com Kluthcouski et al. (2000), a deposição do fertilizante de semeadura, misturado com as sementes da espécie forrageira, em maiores profundidades $(0,07$ a $0,10 \mathrm{~m}$ ), permitiu o atraso da emergência, de maneira a diminuir a competição com a cultura produtora de grãos, semelhante à tecnologia empregada no presente trabalho.

Apesar de não terem sido realizadas análises dos possíveis lucros obtidos com a produção das forrageiras formadas após a colheita da cultura do milho, que no presente trabalho teve como objetivo a formação de palhada para manutenção e continuidade do SPD, verificam-se as altas produtividades de massa seca (PMS) obtidas após a colheita da cultura produtora de grãos (Tabela 2), que poderiam também visar o ganho de peso de animais pelo uso da forragem fornecida no cocho ou em pastejo, dependendo das prioridades adotadas pelo produtor rural.

Analisando-se a produtividade média de grãos do feijoeiro de inverno semeado sobre palhada de $B$. ruziziensis e $B$. brizantha, nota-se que essa variou entre $4.250 \mathrm{~kg} \mathrm{ha}^{-1}$ e $3.971 \mathrm{~kg} \mathrm{ha}^{-1}$, respectivamente, apresentando diferença de $6,57 \%$ na produtividade de grãos entre as espécies forrageiras (Tabela 2). Essa maior produtividade sobre palhada da B. ruziziensis deve-se a sua melhor composição nutricional e bromatológica quando comparada à B. brizantha, o que pode ter promovido melhor nutrição do feijoeiro no processo de decomposição e liberação de nutrientes, corroborando com os resultados obtidos por Pariz et al. (2010), Benett et al. (2008) e Pariz et al. (2011).

Com relação às doses de nitrogênio fornecidas em cobertura para as espécies forrageiras anteriormente ao cultivo do feijoeiro, verificou-se que essas não influenciaram de maneira significativa a produtividade de grãos. Embora o feijoeiro apresente ciclo curto, variando de 90 a 100 dias, provavelmente no período de maior exigência ao $\mathrm{N}$, ou seja, na fase vegetativa e no início da reprodutiva, dos 35 aos 50 dias da emergência da planta (Arf et al., 1999) a decomposição da palhada das braquiárias, aliada à adubação nitrogenada em cobertura da cultura, pode ter suprido a demanda do feijoeiro desse nutriente.

Assim, o cultivo de feijoeiro no sistema plantio direto sob palhadas de plantas de cobertura tem aumentado sua produtividade. Kluthcouski et al. (2000) verificaram que as melhores produtividades de feijão cultivar Pérola foram obtidas em palhada de $B$. brizantha, em comparação com as palhadas de milho, sorgo, soja e arroz. Esses autores não verificaram efeitos positivos da palhada de arroz, que se constituiu no pior tratamento. A palhada de soja 
também não foi benéfica para utilização como cobertura do solo, o que pode estar relacionado tanto com a escassez de cobertura como com a maior incidência de doenças no feijoeiro. Quando se utilizou a palhada de milho, a produtividade do feijoeiro foi $10 \%$ inferior à constatada em palhada de braquiária.

Araújo et al. (2008) conduziram experimento em sistema plantio direto com feijoeiro no município de SelvíriaMS sobre Latossolo Vermelho, em que utilizaram como palhada o milheto, o sorgo forrageiro, o capim-moa e a Brachiaria brizantha e verificaram que não houve interferência nos componentes da produção e na produtividade do feijão de inverno com relação às diferentes espécies de cobertura.

Nesse contexto, Silveira et al. (2005) obtiveram produtividade do feijoeiro cv. Pérola de $1.504 \mathrm{~kg} \mathrm{ha}^{-1}$ sobre palhada de braquiária. De acordo com Garcia et al. (2003), a produtividade do feijoeiro sobre diferentes espécies vegetais como plantas de cobertura foi, em média, de $1.322 \mathrm{~kg} \mathrm{ha}^{-1}$ quando a espécie foi a braquiária. Valderrama et al. (2009), avaliando o efeito de doses de $\mathrm{N}$ e $\mathrm{P}$ em cobertura sobre os componentes de produção e produtividade do feijoeiro de inverno cv. Pérola, irrigado em sistema plantio direto, em que a cultura antecessora foi o arroz, verificaram produtividades em torno de 2.016 a $2.312 \mathrm{~kg} \mathrm{ha}^{-1}$, sendo esses resultados inferiores aos obtidos no presente trabalho.

Dessa forma, pode-se inferir que as produtividades obtidas na presente pesquisa, tanto para a cultura do milho quanto para a do feijoeiro (Tabela 2), foram muito superiores à produtividade média nacional, de acordo com a CONAB (2010). Além desse fato, as plantas forrageiras formadas após a colheita do milho, no período de entressafra, podem ser utilizadas para alimentação animal no cocho ou a pasto, tendo em vista a maior escassez de alimentos nesse período, ou como no trabalho em questão serem utilizadas como biomassa vegetal (palhada) para a semeadura de culturas em sucessão e, portanto, manutenção do SPD.

A receita bruta $(\mathrm{RB})$, que tem relação direta com a produtividade e com os preços médios recebidos pelos produtores, foi satisfatória para todos os tratamentos estudados, indicando que a atividade foi lucrativa em qualquer modalidade de cultivo (espécies e dose de $\mathrm{N}$ - Tabela 2). Desse modo, o lucro operacional (LO), que mede a lucratividade no curto prazo, variou de $\mathrm{R} \$ 2.099,95 \mathrm{ha}^{-1}$ no M/Bb-F 0 a R \$ 3.206,05 ha-1 no M/Bb-F 1, com os melhores resultados econômicos. Nesse caso, o índice de lucratividade (IL), isto é, a taxa disponível da receita bruta que se constitui em lucratividade, após o pagamento de todos os custos operacionais (Martin et al., 1998), atingiu $42,35 \%$. Portanto, as altas produtividades médias obtidas nesta pesquisa foram responsáveis pelos bons resultados econômicos verificados em todos os tratamentos.
Visando à sustentabilidade agropecuária, à redução nos custos de produção e à agregação de valor ao sistema, o tratamento que apresentou melhor desempenho técnico e econômico foi o $\mathrm{M} / \mathrm{Bb}-\mathrm{F} 1$ (milho em consórcio com B. brizantha, $100 \mathrm{~kg} \mathrm{ha}^{-1} \mathrm{ano}^{-1}$ de $\mathrm{N}$ e feijão em sucessão), seguido do M/Br-F 1 (milho em consórcio com $B$. ruziziensis, $100 \mathrm{~kg} \mathrm{ha}^{-1}$ ano $^{-1}$ de $\mathrm{N}$ e feijão em sucessão).

Conforme Allen et al. (2007) e Franzluebbers (2007), os resultados obtidos nos sistemas aqui avaliados refletem os avanços nos aspectos de tecnologia, gestão, produtividade e incremento de lucratividade. Portanto, vale ressaltar a importância de se avaliar o sistema como um todo, com planejamento da sucessão/rotação de culturas mais adequada, visando à sustentabilidade do SPD e integrar sistemas que envolvam lavoura e pecuária (Pariz et al., 2009).

\section{CONCLUSÕES}

O consórcio da cultura do milho com espécies do gênero Brachiaria submetidas a doses de $\mathrm{N}$ em cobertura e o cultivo do feijoeiro de inverno em sucessão apresentaram índices de lucratividade positivos, independentemente do consórcio e da dose de $\mathrm{N}$, indicando a viabilidade das modalidades de cultivo.

O tratamento que apresentou melhor desempenho técnico e econômico foi o milho em consórcio com a $B$. brizantha, adubados com $100 \mathrm{~kg} \mathrm{ha}^{-1} \mathrm{ano}^{-1} \mathrm{de} \mathrm{N}$, parcelados em duas épocas, e cultivo do feijoeiro de inverno em sucessão.

\section{REFERÊNCIAS}

Instituto FNP (2009) Agrianual: Anuário da agricultura brasileira. São Paulo, Instituto FNP. 520p.

Allen VG, Baker MT, Segarra E \& Brown CP (2007) Integrated irrigated crop-livestock systems in dry climates. Agronomy Journal, 99:346-360.

Anghinoni I (2007) Fertilidade do solo e seu manejo em sistema plantio direto. In: Novais RF, Alvares V VH, Barros NF, Fontes RLF, Cantarutti RB \& Neves JCL (Eds.) Fertilidade do solo. Viçosa, SBCS. p.873-928.

Araújo FCM, Pariz CM, Andreotti M, Cavasano FA, Ulian NA \& Buzetti S (2008) Componentes da produção e produtividade do feijão de inverno semeado após o manejo de plantas de cobertura no cerrado. In: $28^{a}$ Reunião Brasileira de Fertilidade do Solo e Nutrição de Plantas; $12^{a}$ Reunião Brasileira sobre Micorrizas; $10^{\circ}$ Simpósio Brasileiro de Microbiologia do Solo; Reunião Brasileira de Biologia do Solo, Londrina. Anais, Embrapa soja: IAPAR/UEL. CD-ROM.

Arf O, Silva LS, Buzetti S, Alves MC, Sá ME, Rodrigues RAF \& Hernandez FBT (1999) Efeito da rotação de culturas, adubação verde e nitrogenada sobre o rendimento do feijão. Pesquisa Agropecuária Brasileira, 34:2029-2036.

Benett CCS, Buzetti S, Silva KS, Bergamaschine AF \& Fabricio JA (2008) Produtividade e composição bromatológica do capimMarandu a fontes e doses de nitrogênio. Ciência e Agrotecnologia, 32:1629-1636. 
Borghi E \& Crusciol CAC (2007) Produtividade de milho, espaçamento e modalidade de consorciação com Brachiaria brizantha no SPD. Pesquisa Agropecuária Brasileira, 42:163-171.

Companhia Nacional de Abastecimento - CONAB (2010) Acompanhamento da Safra Brasileira de Grãos 2009/2010. Décimo Segundo Levantamento. Disponível em: <http:// www.conab.gov.br>. Acessado em: 14 de setembro de 2010.

Franzluebbers AJ (2007) Integrated crop-livestock systems in the Southeastern USA. Agronomy Journal, 99:361-372.

Garcia CMP, Andreotti M, Tarsitano MAA, Teixeira Filho MCM, Lima AES \& Buzetti S (2012) Análise econômica da produtividade de grãos de milho consorciado com forrageiras dos gêneros Brachiaria e Panicum em sistema plantio direto. Revista Ceres, 59:157-163.

Garcia RN, Fornasieri Filho D \& Rossato Júnior JAS (2003) Influência de cultura de cobertura morta e nitrogênio sobre os componentes produtivos da cultura do feijoeiro de inverno em sucessão a cultura do milho. In: Congresso Brasileiro de Ciência do Solo, Ribeirão Preto. Anais, Sociedade Brasileira de Ciência do Solo. CD-ROM.

Kluthcouski J \& Aidar H (2003) Uso da integração lavoura-pecuária na recuperação de pastagens degradadas. In: Kluthcouski J, Stone LF \& Aidar H (Eds.) Integração lavoura-pecuária. $1^{\mathrm{a}}$ ed. Santo Antônio de Goiás, Embrapa Arroz e Feijão. p.185-223.

Kluthcouski J, Cobucci T, Aidar H, Yokoyama LP, Oliveira IP, Costa, JLS, Silva JG, Vilela L, Barcellos AO \& Magnabosco CU (2000) Sistema Santa Fé - tecnologia Embrapa: integração lavoura-pecuária pelo consórcio de culturas anuais com forrageiras, em áreas de lavoura, nos sistemas direto e convencional. Santo Antônio de Goiás, Embrapa Arroz e Feijão. 28p. (Circular técnica, 38).

Kluthcouski J \& Yokoyama LP (2003) Opções de integração lavoura-pecuária. In: Kluthcouski J, Stone LF \& Aidar H (Eds.) Integração lavoura-pecuária. $1^{\mathrm{a}}$ ed. Santo Antônio de Goiás, Embrapa Arroz e Feijão. p.131-141.

Landers JN (2007) Tropical crop-livestock systems in conservation agriculture: the Brazilian experience. $1^{\mathrm{a}}$ ed. Rome, FAO. 92p.

Macedo MCMM (2009) Integração lavoura e pecuária: o estado da arte e inovações tecnológicas. Revista Brasileira de Zootecnia, 38:133-146.

Martha Júnior GB \& Vilela L (2007) Resultado econômico e estratégias de intensificação da adubação de pastagens. In: Martha Júnior GB, Vilela L \& Sousa DMG (Eds.) Uso eficiente de corretivos e fertilizantes em pastagens. Planaltina, Embrapa Cerrados. p.69-92.

Martin NB, Serra R, Oliveira MDM, Ângelo JÁ \& Okawa H (1998) Sistema integrado de custos agropecuários "Custragri". Informações Econômicas, 28:7-28.
Montes SMNM, Firetti R, Golla AR \& Tarsitano MAA (2006) Custos e rentabilidade da batata-doce (Ipomoea batatas L.) na região oeste do Estado de São Paulo: estudo de caso. Informações Econômicas, 36:15-23.

Muniz LC, Figueiredo RS, Magnabosco CU, Wander AE \& Martha Júnior GB (2007) Análise econômica da integração lavoura e pecuária com a utilização do system dynamics. In: Congresso da Sociedade Brasileira de Economia, Administração e Sociologia Rural, Londrina. Anais, SBEASR. CD-ROM.

Pariz CM, Andreotti M, Azenha MV, Bergamaschine AF, Mello LMM \& Lima RC (2010) Massa seca e composição bromatológica de quatro espécies de braquiárias semeadas na linha ou a lanço, em consórcio com milho no sistema plantio direto na palha. Acta Scientiarum. Animal Science, 32:147154.

Pariz CM, Andreotti M, Buzetti S, Bergamaschine FA, Ulian NA, Furlan LC, Meirelles PRL \& Cavasano FA (2011) Straw decomposition of nitrogen-fertilized grasses intercropped with irrigated maize in na integrated crop livestock system. Revista Brasileira de Ciência do Solo, 35:2029-2037.

Pariz CM, Andreotti M, Tarsitano MAA, Bergamaschine AF, Buzetti S \& Chioderoli CA (2009) Desempenhos técnicos e econômicos da consorciação de milho com forrageiras dos gêneros Panicum e Brachiaria em sistema de integração lavourapecuária. Pesquisa Agropecuária Tropical, 39:360-370.

Richetti A \& Ceccon G (2010) Estimativa do Custo de Produção do Milho Safrinha 2010, em Cultivo Solteiro e Consorciado com Brachiaria ruziziensis, na Região Sul de Mato Grosso do Sul. Dourados, Embrapa Agropecuária Oeste. 7p. (Comunicado técnico, 157).

Santos HG, Jacomine PKT, Anjos LHC, Oliveira VA, Oliveira JB, Coelho MR, Lumbreras JF \& Cunha TJF (2006) Sistema Brasileiro de classificação dos solos. $2^{\mathrm{a}}$ ed. Rio de Janeiro, CNPS. $306 \mathrm{p}$.

Silveira PM, Braz AJBP, Kliemann HJ \& Zimmermann FJP (2005) Adubação nitrogenada no feijoeiro cultivado sob plantio direto em sucessão de culturas. Pesquisa Agropecuária Brasileira, 40:377381 .

Tracy BF \& Zhang Y (2008) Soil compaction, corn yield response, and soil nutrient pool dynamics within an integrated croplivestock system in Illinois. Crop Science, 48:1211-1218.

Valderrama M, Buzetti S, Benett CGS, Andreotti M, Arf O \& Sá ME (2009) Fontes e doses de nitrogênio e fósforo em feijoeiro no sistema plantio direto. Pesquisa Agropecuária Tropical, 39:191-196. 